\title{
LA PROBLEMATICA ACTUAL DE LA IMMIGRACIO A CATALUNYA: UN NOU MODEL D'ESTUDI CULTURAL
}

\author{
Pere Negre \\ (Universitat de Barcelona)
}

La problemàtica de la integració cultural dels immigtants a Catalunya pot considerar-se com el tema més original de la sociologia catalana. Sense rebutjar els aspectes econòmics, socials i polítics del problema, convé definir-lo i tractar-lo en el marc antropològic, ja que la cultura té la seva pròpia autonomia. La possible discriminació social i econòmica que sofreixen la majoria dels immigrants que procedeixen de les regions rurals de la testa d'Espanya i formen el gros de la classe obrera catalana es tradueixen en l'àmbit cultural en processos de dominació-opressió, segons la terninologia de Pablo Freire, que caldria aplicar al cas català amb modificacions importants. 


\section{Introducció}

No cal insistir en la importància de la immigració a Catałunya, la regió d'Espanya amb més creixement demogràfic, a causa d'aquest factor. ${ }^{1}$ Catalunya, des dels seus orígens, segons histotiadors i sociólegs, és una «terra de marca», formada per onades migratòries de molt diversa índole. La peculiaritat del cas és la importància excepcional que adquireix per al desenvolupament industrial català l'atracció de mà d'obra de la resta d'Espanya en la segona meitat del segle xIx i principis del segle actual, a mesura que aquest país va consolidant la revolució industrial.

Encara que aquest procés té la seva pròpia originalitat i dinamisme, està lifigat evidentment al desenvolupament econòmic i polític de la resta de I'Estat espanyol. En la dècada dels anys seixanta, després del Pla d'Estabilització, s'inicia un procés d'industrialització accelerada. A pesar dels canvis polítics (presència de la tecroctàcia en el govern) $i$ econòmics (abandonament definitiu de l'autarquia) els successius Plans de Desenvolupament i la creació artificial dels «pols industrials» incrementen i consoliden en un altre nivell el desenrotllament desigual i combinat de la península. Les migracions interiors (i exteriors) de mà dobra rural vers la indústria es qualifiquen com l'esdeveniment més important a Espanya en els darrers vinti-cinc anys, tant en el pla social com en el cultural. ${ }^{2}$ No és estrany; doncs, que els efectes del colonialisme intern degut a aquest desenvolupament desigual es prestin a distintes interpretacions $i$ denúncies, sobretot en aquests darrers anys de major libertat intellectual. ${ }^{3}$

1. Aquest article forma part d'un treball d'investigació sobre: «La immigració a Catalunya i a Tarragona», que es publicarà, fet per encàrrec de l'ICESB.

2. Informe FOESSA (1975), pp. 67 ss.

3. Cuadernos para el diálogo (maig, 1974, suplement). Qüestions de vida cristiana, 1966, núm. 31. «La immigtació». 


\section{Procés cultural, procés polèmic}

Les migracions interiors degudes a la industrialització són fenòmens bastant típics d'altres països mediterranis (Itàlia, Portugal, Grècia) en la mateixa època, però ałlò que distingeix aquesta migració, així com la del País Basc, és la presència d'una forta identificació ètnica de la regió. La "qüestió catalana», fruit d'una històtia i una tradició que endebades tractà d'enterrar la política centralista dels anys de la dictadura, converteix el problema de la immigració en un dels més candents. Per això, quan co. mença a sorgir novament la discussió sobre la nacionalitat catalana, el llibre de Francesc Candel Els altres catalans empalma, sense ésser-ne molt conscient, amb tota una tradició en un context nou i més angoixós. ${ }^{4}$

Aquesta literatura de postguerra, retardada per la repressió cultural generalitzada, sobretot en la dècada dels quaranta, té el mèrit de desterrar per sempre els tons més explícits d'un nacionalisme romàntic i les seves seqüeles de prejudicis o racismes, però no aconsegueix d'oblidar la vella «qüestió lerrouxista», quan el pais torna a expressar-se i afimar-se políticament. ${ }^{5}$

La polèmica que Jordi Pujol va tenir el mèrit d'estrenar en la dècada dels anys cinquanta, abans que esclatessin els brots més significatius d'opo sició al franquisme, s'ha convertit en el "tema de la sociologia catalana»" Bastants anys després, el procés de descomposició del tègim i el curt $i$ intens camí vers la legalitat democràtica porta la discussió al carrer. ${ }^{7}$ Els partits es fan ressò de la mateixa polèmica $i$ han de definir-se clarament a

4. Barcelona (Edicions 62, 1964). La discussió abans de la guerra pot esbrinar-se a través del llibre de Vandellós La immigració a Catalanya (Barcelona, 1935).

5. Conversaciones sobre inmigracion interior (Barcelona: Patronato Municipal de la Vivienda, 1964). J. M. Martínez, La immigració a Barcelona (Barcetona, 1964). Ramon Dalmau, A. Jutglar, J. M. Martínez i altres: La immigració a Catalunya (Barceiona: Edició de Materials, 1968). Quaderns d'alliberament (1978), núms. 2 i 3, «La immigració als Països Catalans». Es pot veure en aquest recuil progressiu d'articles com van sorgint, a partir dels anys seixanta, les diverses temàtiques, segons el temps. Comparant aquests escrits amb la cèlebre obra de Vandellós o fins $\mathrm{i}$ tot amb els primers escrits de Francesc Candel es nota certament que s'han superat vells prejudicis i estereotips.

6. En el llibte de I. Pujol, La immigració, problema i esperança de Catalunya (Barcelona: Nova Terra, 1976), es recullen textos d'aquest autor des dels anys 1958.

7. Un resum d'aquesta polèmica que inicia Jordi Pujol es pot llegir amb les degudes referències bibliogtàffques en l'article de Rafael Castellanos «El debat sobre la interpretació dels immigtats a la societat catalanas, a Quaderns d'alliberament, op, cit, pp. 173-230. Amb la promesa d'eleccions quan s'enceta el govern Suárez, els diaris locals de Batcelona perllonguen la discussió anterior, assenyalant el pensament dels dirigents de diversos partits sobre la integració. 
causa de la importància del vot immigrant. Els vells problemes adquireixen de cop i volta la seva força en un context nou i apressant.

\section{Une nova perillositat}

Lligada a la mateixa supervivència de la cultura i del nacionalisme en aquest país, sorgeix - -segons el parer de molts- la possibilitat d'una separació i fins i tot d'un enfrontament entre els diversos grups ètnics. Això que fou impossible, a pesar del fenomen lerrouxista, en el passat, és avui una amenaça per raó d'una sèrie de factors no precisament «culturals». El més sentit i denunciaz d'ells és, no hi ha dubte, l'evident manipulació ideològica anticatalanista de l'immigrat per tal d'amagar els anys 40 i 50 el problema pendent de la reforma agrària espanyola. No endebades el go vern era defensat obertament per grups latifundistes $i$ banquers els ingressos dels quals provenien de la superexplotació de les regions més endarrerides d'Espanya.

L'aillament $i$ el recel que produí el tègim a l'Occident vencedor del feixisme, van fer més necessàries que mai aquestes vinculacions amb el capital especulatiu d'origen rural. Encara que per la seva ideologia ruralista i tradicionalista el govern volgué seguir una política restrictiva, contenint l'emigració, una vegada més va sacrificar pragmàticament els seus principis beneficiant aquells que el sustentaven. ${ }^{8}$

Tot i que s'intentava a tota costa un desenrotllament industrial autàrquic (impossible sense la vella ajuda de l'Alemanya nazi), la ideologia marcadament antiurbana i ruralista explotava els uns i els altres manipulant la qüestió catalana a favor seu. Per als catalans això significà tornar als anys més crus de repressió cultural. Per als immigrats significà la manipulació d'ells mateixos, donant-los una identitat espanyola i enfrontantlos a la llengua del país d'acoliment. La manipulació negativa del fet català per part d'aquella primitiva passió centralista que va pretendre identificar-se amb una nació abstracta, menyspreant les nacionalitats que la configuraven, no va convèncer igualment tots els immigrats, sinó sobretot aquells que, pel seu origen regional o pel seu estatus, volien diferenciar-se de la resta i se sentien els nous conquistadors i avançat: d'aquesta colonització intellectual. ${ }^{9}$

8. Vegeu alguns comentaris d'aquesta política migratòria des dels anys quaranta i cinquanta a «La immigració als Països Catalans», de diversos autors, a Alliberament (agost de 1974, núm. 1), pp. 6-19, o a l'informe FOESSA, 1975, op. cit., pp. 61 ss.

9. Ens referim a l'actitud que - segons alguns autors- reffecteixen aiguns furcionaris, professionals o fins i tot gent que venen de les tegions castellanes. Aquest 


\section{El model «catala» de desenvolupament}

Tot i la indubtable repercussió d'aquests fenòmens en l'actualitat, convé desconfiar una vegada més de les explicacions sociològiques basades en un sol factor. La política migratòria centralista que comentàvem es combinà $a m b$ la dinàmica pròpia d'un procés d'industrialització, ja traditcional a Catalunya, basat en un model d'explotació extensiva de mà d'obra barata i no qualificada, en comptes d'una explotació intensiva del capital. ${ }^{10}$ Així es va donar una convergència, moltes vegades inconscient, entre el centralisme del règim i el colonialisme regional, secundat per certs grups de la burgesia local, per més que aquesta vulgui avui escudar-se en la seva manca de control polític del model econòmic que ajudava a consolidar."

És evident que avui la quiestió central —com assenyala Jordi Pujolresideix en la capacitat $i$ en la conquesta d'un poder polític propi a Catalunya, que li permeti controlar els seus destins. Petò la frase té una excessiva ambigüitat. Tant o més important que aquesta afirmació és la primera de les qüestions polítiques que tot home ha de plantejar-se: ¿Quins són els interessos locals $i$ els grups o persones que tindran un paper protagonista en aquesta marxa vers l'autogovern? ¿Quina és la representació real d'aquells que viuen $\mathrm{i}$ treballen a Catalunya $\mathrm{i}$ desenrotllen aquest país, encara que no van néixer aquí? ¿Quina política se seguirà realment sobre el problema nacionalista, més enlià de les promeses i eslògans electorals i quins interessos econòmics la definiran?

Els problemes polítics del passat, encara pendents, no impedeixen doncs que molts homes responsables s'enfrontin al gxan desafiament de Ihora actual. Tant o més decisiva que la superació política del centralisme i de l'antinacionalisme regional del règim anterior, és l'actual crisi del model de desenvolupament català que ha posat en evidència la crisi mundial. Crisi econòmica, social i política a la vegada, si no volem caure en dicotomies perilloses o ideologitzades. ${ }^{12}$

problema va ésser moit debatut $\rightarrow$ a propòsit del funcionariat- en una trobada recent sobre la immigració el 3 i 4 de juny de l'any 1978 a l'Ametlla del Vailles, organitzada per les fundacions J. Bofill i Serveis de Cultura Popular.

10. Vegeu E. Pinilla de las Heras, Los empresarios catalanes y el desarrollo capitalista. El caso catalán (Barcelona: Península, 1968), i J. Muntaner i Pascual, «Aspectes económics de la immigració a Catalunya, a Qüestions de vida cristiana, op. cit., pp. 49.78 .

11. Vegeu Yordi Pujol, La immigració, problema i esperança de Catalunya, op. cit, pp. 73 i ss.

12. Ens referim més que tot a l'hàbit de separar l'aspecte social de l'econònic i que indica ja una postura presa d'antuvi. Aquesta nostra argumentacio està inspirada 


\section{La formulació social del problema}

Deixant de banda el problema de la immigració funcionarial i professional, amb els trets específics que evidentment la caracteritzen i les seves incidències en la quiestió catalana, ens centrarem en la major proporció de no-natius que configuren la mà d'obra catalana, de procedència rural. ${ }^{13}$ En l'aspecte laboral s'han assenyalat els desavantatges del model de desenrotllament industrial a què ens teferiem: escassa mobilitat, sobretot en la primera generació, mobilitat més aviat tècnica i no professional o administrativa, etc. ${ }^{14}$ En el que tothom coincideix és en la inferioritat de condicions d'aquesta immigració respecte a allò que podríem anomenar un «salari indirecte», com l'estatge o el barri. Una explicació del fenomen seria que les empreses foren les primeres a beneficiat-se de tota una infiastructura urbana, desentenent-se en part de la «teproducció» de la mà d'obra. ${ }^{15}$

La ciutat i els seus problemes moderns són mirats, a més a més, des d'un punt de vista cultural, que és el que a nosaltres més ens interessa. Els grans cinturons habitacionals esparsos tot al llarg de les vies de co. municació, en els municipis que voregen la metròpoli, han fet possible l'«oblit mutu» en què avui sembla desenvolupar-se la vida quotidiana d'aquests dos grups ètnicament diferenciats, tot i que encara existeixen bartis d'un cert «mestissatge». La bartera és cultural, però caldrà veure si ve mediatitzada per factors socials, econòmics, urbanístics.

Per als més pessimistes els «bartis de tefugi» son un autèntic mur que conté la integració no solament cultural, sinó urbana, és a dir, l'ad. quisició d'una cultura o estil de vida ciutadans, tal com ho caracteritzava Louis Wirth. ${ }^{16} \mathrm{Els}$ qui veuen la integració com un procés més complex -el protagonisme principal del qual l'exerceix l'immigrat- que es dóna preci-

en l'orientacio de les obres de V. Pérez Díaz, especialment Pueblos y closes sociales en el campo español (Madrid: Siglo XXI, 1974), pp. 290 i ss.

13. Ens referim evidentment als grans centres industrials.

14. Vegeu E. Pinilla de las Heras, Immigració $i$ mobilitat social a Catalunya (Barcelona: ICESB, 1975), 5 vols.; C. Esteva Fabregat, comentant una encuesta seva, ens parla del model d'estratificació $i$ de la presència majoritària de catalans en els estrats alts, així com de la mobilitat dels immigrats trebaliadors ( «Aculturación y urbanización en Barcelona», Etbnica, núm. 5, 1973, pp. 135-189, p. 55: «Inmigtación, etnicidad y reiaciones interétnicas en Barcelona», Etbnica, núm. 6, 1973, pp. 71-129, pp. 107 i ss.).

15. Cfr. J. Borja, Por una política municipal democrática (Barcelona: Avance, 1977), p. 23.

16. «The Urbanism as a way of Life»: American Journal of Sociology, núm. 44 (juliol de 1938), pp. 1-24. 
sament en la Iluita social, a vegades són bastant més optimistes. A més de la reivindicació estrictament laboral, parlen de la liuita pel salari indirecte: la reivindicació de la ciutat. ${ }^{17}$

Certament, les lluites socials s'han desdoblegat en aquests darrers anys en moviments $i$ organitzacions sindicals $i$ en una mobilització popular el protagonisme dels quals han capitalitzat sobretot les associacions de veïns de molts d'aquests barris obrers.

\section{Conflicte de classes, conflicte ètnic}

D'una altra banda, dins d'aquesta visió del problema no manquen tampoc els pessimismes, que provenen del fet que el conflicte de classes (o la «lluita de classes»), encara que teòricament estaria lligat a la reivindicació nacionalista del país, no comptaria amb suficients experiències ni constituiria un element important de la consciència collectiva (o de la consciència de classe). En altres paraules, la reivindicació de Catalunya, com a projecte específic de nova relació de poder i cultura respecte a l'Estat espanyol no seria, per a la major part de les classes populars que han de definir aquest projecte i donar-li el seu contingut més especific, un objectiu clar, ligat als seus interessos immediats. ${ }^{18}$ Encara que el grau de suport popular que ha obtingut darrerament la reivindicació política de Catalunya i el seu estatut modificaria en part aquest judici negatiu, s'assenyala també, amb gran realisme i penetració psicològica, que aquesta reivindicació no es donatia en l'àmbit de la quotidianitat. La llengua, la cultura, etc., quan s'adapten, tenen - la majoria de les vegades- un caràcter instrumental per a l'immigrat obter amb finalitats de «promoció individuał» $i$ «adaptació a l'esquema dominant».

Si en comptes d'integració a la ciutat o integració a la cultura parlem, com Lefebvre, d'un "dret a la ciutat» i hi afegim la reivindicació de la cultura catalana, no sembla que aquests dos fenòmens vagin molt lligats a la consciència dels qui es veuen exclosos socialment $i$ culturalment de la societat en els nous ghettos urbans. Més aviat semblaria que aquesta reivindicació de la ciutat hauria d'anar acompanyada aleshores d'un fort etnocentrisme. Molts factors impedeixen el sorgiment d'aquest etnocentrisme de classes (l'escassa identificacio ètnica que duen els im-

17. H. Lefebvre, El derecbo a la ciudad (Barcelona: Ed. Península, 1969).

18. A. C. Comín i J. N. García Nieto, Juventud obrera y conciencia de clase (Madrid: Edicusa, 1974), ens parten en aquest sentit d'una manca de praxis o pràctica social (pp. 37-38). 
migrats, el sentit progressista de la majoria de les reivindicacions cata. lanistes, la mobilitat social que suposa la mera adaptació instrumental de la llengua, costums, etcètera). Sigui com sigui, l'alliberament de classe no va en la pràctica acompanyat, segons alguns sociòlegs, de l'alliberament nacionalista. ${ }^{19}$

\section{Sociologia de les migracions o antropologia de la aculturació?}

S'ha assenyalat la importància d'una discussió més teòrica de l'assumpte, basada en el marc de la sociologia de les migracions. Però pel seu caràcter dispers i generalitzador, a partir d'experiències particulars, aquesta branca de la sociologia no s'interessa directament pel problema que ens ocupa, el de la integració cultural entre aquells que emigren dins d'un mateix Estat, sinó que parteix més aviat de conflictes ètnico-racials entre grups dins d'un marc més general: la migtació de mà d'obra estrangera.

L'orientació antropològica és més rica ja que és en aquest camp on s'han fet, a la meva manera de veure, les millors aportacions sobre el problema de la immigració a Catalunya i la integració.

Si la cultura té una autonomia — per més relativa que sigui- imposa també les seves pròpies regles de funcionament i models teòrics amb els quals hem d'interpretar el fet social. La cultura, en la seva arrel, és un fenomen d'interpretació del món i, per tant, d'obertura, a pesar de totes les temptacions etnocentristes. I això cal afrmar-ho en el cas català, on la presència d'altres cultures, més o menys desdibuixades o fortes, és aclaparadora des d'un punt de vista quantitatiu.

S'ha parlat en aquest sentit de la aculturació i els seus nivells quan es diferencia la integració de l'adaptació per una banda o d'una assimilació passiva. S'arriba així a postular un procés dialèctic, sempre lihure $i$ creatiu, en el qual l'adopció dels costums, la llengua i altres normes cul-

19. Es el que deduïm de diverses intervencions a la trobada a l'Ametlla det Vallès (cfr. nota 9). A. C. Comín i J. N. García Nieto diuen que sno existe una sole visión de Cataluña que tendría todas las prerrogativds de aufenticidad y que babria que acatarse con sumision reverencial» (Juventud obrera y conciencia de clase, op. cit., p. 36), i de forma bastant més esquemàtica i dicotòmica, l'articie d'A. Izquierdo, Rosa Junyent $\mathrm{i}$ altres «Sobre el problema de la integración socio-cultural de los inmigrados en Catalunya» parla d'una cultuta i una Catalunya nova en la qual «los inmigrantes son elemento clave en la conquista de esta begemonia en lo cultural y en lo social, en la vertebración de la nueva sociedad i cultura catalanas (Materiales, maig-juny de 1978 , pp. 57-72, p. 71), sense dir-nos ben clar si això seria una altra nació o cultura sense continuïtat amb l'actual. 
turals per part dels no-natius suposaria una nova interpretació del «fet català» $a m b$ aportacions específiques $\mathrm{i} a m b$ un protagonisme principal exercit pels immigrats. Ningú no fa tabula rasa del que fou i continua essent. Es tracta d'una teorganització de la pròpia petsonalitat basada en certs nuclis $i$ identitats que deixen a la vida collectiva tota la seva iniciativa quant a contínua revisió social de valors, normes, comportaments collectius.

La majoria dels estudis sobre la immigració a Catalunya parteixen d'una opció clara: la defensa cultural i la reivindicació nacionalista de Catalunya. Es tracta d'un judici de valor que també fem nostre, però no perquè creguem que tota cultura i nacionalitat, per principi, hagin de ser defensats $i$ reivindicats prescindint de les circumstàncies i continguts concrets. Creim, amb Pablo Freire, que darrera dels contactes, conflictes i processos d'aculturació (siguin aquests adaptatius, integratius o assimilatius) es dóna sempre la presència d'elements de dominació $i$ això complica enormement el problema més enllà del camp mateix de la cultura, en el de la poltica. Des d'un punt de vista polític caldria tevisat doncs un postulat tan general i abstracte com el de la «bondat intrínseca» de la integració.

\section{La cultura com a fet popular ${ }^{20}$}

L'antropologia parteix d'una definició de cultura que la diferencia, en primer lloc, de l'erudició o cultura acadèmica, literària, artística. En principi, per a l'antropologia no existeix una persona més culta que una altra, La cultura d'una collectivitat és el seu quefer diari, la seva llengua, els seus costums i normes de vida collectiva basats en una escala de valors implícita. En tot cas, les diferències personals o de grups es produeixen aquí pel grau de socialització-aculturació dels membres de tal comunitat. Plantejar-se, doncs, el major o menor nivell cultural en l'àmbit de la integració de dos o més grups ètnics a una cultura, resultaria no solament discriminatori sinó mancat de base científica. L'ertor, encara que no afecta les tesis fonamentals de Jordi Pujol, ha contribuït a encendre no poques polèmiques, desviant gairebé sempre l'atenció sobre els seus progressistes plantejaments de base. ${ }^{21}$ Tot l'assumpte pot discutir-se a un niveII

20. La idea de la importància del «poble» o «nacionalitat» de Jordi Pujol no ens hauria de portar a defensar sempre o gairebé sempre aquest valor, prescindint de les seves circumstàncies històriques. Cfr. La inmtigració, problema $i$ esperança de Catalunya, op. cit., p. 61 i ss i 106 i ss. Alguns autors assenyalen el catàcter abstracte d'aquesta filosofia del poble.

21. Considerem, a pesar de tots els seus atenuants, bastant inoportunes o infun- 
més tècnic i neutral parlant d'una identitat ètnica més feble en certes regions o collectivitats (com en el grup andalús) com a resultants d'un procés de dominació sobre el qual existeix un cert consens. Però el ptoblema no es resol només explicitant els termes polítics (i els seus possibles condicionants econòmics), sinó introduint aquest concepte de dominació en l'antropologia. És el que intenta Pablo Freire en parlar de cultures dominants 1 cultures optimides. ${ }^{22}$

Per tal d'apropar més aquest enfocament val la pena partir del terme de «cultura popular», per bé que es tracta evidentment d'una redundància (tota cultura és un fet eminentment popular). Però aixi descartem tota tendència elitista o tota comparació entre cultures a base de supremacies que amaguen el seu major o menor grau de «domini» o «opressió».

Una vegada assentat aquest primer pla podem reintroduir el ptoblema de l'erudició amb la distinció entre «cultura illetrada» i «cultura lletrada», al marge de tota opressió. I de cultures més o menys lletrades, segons que es vegin reflectits els seus elements populars pels artistes, intellectuals $i$ fins $i$ tot tècrics. L'absència d'elitismes o dominacions ens duria possiblement al concepte d'《intellectual orgànic» de Gramsci, per tal d'assenyalar els autèntics representants d'aquuesta cultura popular.

En tot cas, l'aplicació d'aquest model a la realitat concreta, on es produeixen factors de dominació-opressió complexos, es veurà mediatitzada per una variable política (el centralisme de l'Estat espanyol) i una altra d'econòmica (el model català de desentotllament). No obstant això, l'esquema no és tan simple, ja que a tot tipus de dominació política hi correspon un altre tipus de dominació econòmica i a la invetsa, per més que aquestes dues estructures de dominació no coincideixin ni puguin convertir-se en un simple epifenomen o reflex.

En el cas català, es dóna un cert tipus de dominació econònica d'altres grups ètrics, sense la corresponent dominació política. ${ }^{23}$ Però no hi pot mancar - per a la mateixa consolidació del model econòmic de domi-

dades les seves expressions sobre l'immigxant andalús (Immigració, problema $i$ esperonça de Catalunya, op. cit., p. 68), que tanta polèmica van suscitar.

22. El pensament de P. Freire, que aqui no desenvolupem, es pot treure de la seva obra més coneguda, Pedagogía del oprimido (Montevideo: Tierra Nueva, 1970). Vegeu també els textos escollits per I'INODEP: El mensaje de Paulo Freire. Teoría y práctica de la liberación (Madrid: Mansiega, 1972).

23. Aquest argument tan utilitzat s'ha de matısar, car tot pocer polític té els seus determinismes en l'econòmic. Caldria parlar més aviat d'un gran desfasament o nocorrespondencia entre ambdós. Ed que segueix al text explica on es desplaça el poder polític. En tot cas, el futur polític de Catalunya és un gran repte per a tothom, ja que amb la progressiva autonomia l'argument deixa d'ésser vàlid en part. 
$\mathrm{ni}$ - la presència insubstituible dels «astuts», en terminologia freiriana. Són aquells estrats de la població que, mitjançant la seva adaptació oportunista als esquemes polítics de dominació centralista, fan possible la per* petuació del model de desenvolupament local dominant. Aquest fet, que constitueix una excepció $i$ un atzar enfront de la permanència del «fet català», no és tan excepcional respecte del model de dominació econòmica que s'imposa i que ajuda a consolidar.

\section{Cultura oprimida: autèntica cultura}

En el continum cultura alliberada - cultura optimida hi cal situar evidentment la cultura catalana vers el pol de l'alliberament -a pesar d'una llarga història d'opressió cultural-, si la comparem amb la cultura d'altres grups ètrics com l'andalús, majoritati en la immigració. Aquest seria desplaçat vers el pol oposat de l'opressió, a pesar dels actuals aires d'alliberament que avui es respiren en aquella regió.

Sigui com sigui, una cultura oprimida no és una cultura que desapa. reix. El recanvi d'un nucli organitzador de la personalitat per un altre no és un procés tan simple $i$ adialèctic com podria semblar. Ĺa cultura oprimida, en altres paraules, gairebé mai no desapareix. En l'àmbit cultural és possible sempre la revenja, cosa que no passa en l'esfera política, base de la dominació. Existeix en gairebé tots els pobles dominats una gamma de formes de protesta cultural que quasi gosatiem batejar amb aquell terme de «protesta ideal», que Marx aplicava a la religió, si no fos pel sentit pejoratiu $\mathrm{i}$ antipràctic d'aquest concepte marxista. Igualment com la «protesta ideal» religiosa s'ha convertit moites vegades en ferment de revolucions, el folklore té elements incalculables de tebelilia amagada, que s'expressen en termes de marginalitat, pobresa, tristesa o alegria d'allò no plenament dominat en la seva subjectivitat. Tots aquests elements poden adquirit de sobte un sentit totalment distint en nous contextos d'interpretació política de la realitat.

En el cas andalús és notori el fet que el folklore «s"hagi venjat» ja «idealment», sobre altres expressions de l'espanyolitat, monopolitzant de cara a l'«exportació» el «fet espanyol» o "castellà», segons els gustos. Quan parlarem, per tant, de respecte a les identitats culturals, cal tenir en compte tot això. 


\section{Els nous determinants socials del problema}

Més enIlà de certs mecanismes de defensa que trastladarien la dominació econòmica al camp cultural (prejudicis, estereotips, discriminacions) és evident que no s'ha donat a casa nostra una expoliació cultural d'altres grups ètnics, semblant a la que dugué a terme el centralisme dins i fora d'Espanya (la conquesta americana constitueix, a pesar de tots els mites sobre la mestissització, el més negatin del cas). Els qui ens parlen, a partir de dades empíriques, de la conflictivitat de classes i les seves lluites, recalquer la no-coincidència entre Ia consciència ètnica i la consciència de classes, encara que existeixen evidents superposicions i condicionaments. ${ }^{24}$

També cal estar atents als nous determinants socials i polítics de la integració. Entre els primets volem destacar la presència actual d'un contingent no català de dimensions no conegudes fins ara. Fet demogràfic que no tindria consequències socials específiques si no es combina amb el de

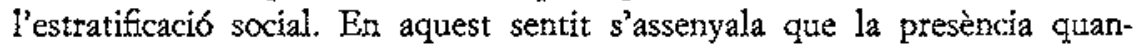
titativa majoritària de la immigració en la classe obreta i gairebé absoluta en les seves capes menys qualificades, pot $i$ ha de transformar-se en un nou model qualitatiu del conflicte entre classes, dins del qual cal contemplat el procés d'integració. EI nou determinant polític fonamental seria conseqüència de la progressiva conquesta d'un poder polític en la regib.

$\mathrm{Si}$ ens fixem en el sentit històric de la reivindicació nacionalista de Catalunya, i la seva possibilitat d'èxit, quan s'ha ligat amb les aspiracions progressistes d'altres camps (econòmic, polític, educacional, sanitari, etcètera), és evident que ens veiem obligats a emetre judicis de valor sobre el futur i a parlar de la «bondat relativa» d'aquesta vella lluita per la pròpia cultura. El nou determinant polític, doncs, hauria d'ésser considerat com a altament positiu.

Quant a la major presència de no-natius a Catalunya, és evident que això constitueix una negativitat més aviat des del punt de vista de la regió d'origen (retard indefinit de la reforma agtària en un principi i transformació actual de l'estructura agrària d'aquesta i altres regions espanyoles $)^{25}$ Des del punt de vista de la tegió de destí - Catalunya- els judicis negatius o positius són totalment ineficaços. Els immigrats estan inserits en la producció d'aquest país i en són part essencial, contribuint com a

24. C. E. Fabregat, «Immigració i confirmacio ètnica a Barcelona», a Quaderns d'alliberament, op. cit., pp. 78 i ss.

25. Sobre aquest terna, vegeu V. Pérez Díaz, Pueblos y clases sociales en el campo español, op. cit, pp. 19 i ss.; i Emigración y saciedad en la tierra de campos (Madrid: Estudios del Instituto de Desartollo Económico, 1969), pp. 19 i 40. 
primera $i$ ptincipal força al desenrotllament econòmic que coneixem. En tot cas, la regativitat o positivitat més objectiva vindrà donada per la nostra anàlisi específica de tal desentotlament i model d'acumulació.

\section{Els judicis de valor i les seves limitacions}

El que sí que hem de fer -des de l'òptica cultural en què ens col. loquem a base d'un judici històric (la progressivitat del fet català) - és assenyalar les possibles negativitats d'una aculturació instrumental o «adaptació», a causa del fet que la cultura i la llengua catalanes s'han convertit en part en un instrument de promoció social per als possibles «astuts» entre la massa immigrant. L'adaptació cultural no aniria llavors en el sentit d'una revisió de l'actual model d'acumulació sinó que ajudaria a perpetuar-lo. Tampoc no significaria un pas substantiu vers una major democràcia real. L'ambigüitat del terme integració (integració a una comunitat ètnica, a una història, a una terra), sense tenir en compte jerarquies i grups de dominació i la conflictivitat social, significaria en darrer terme una reproducció cultutal d'un esquema de dominació política basada en el no-qüestionament dels poders fàctics.

Però pretendre que la «qüestió nacional» està desiligada de la «qüestió social» o que aquesta és només un «condicionant», seria tan absurd com teduir el problema nacionalista en l'aspecte cuitural a la simple disjuntiva entre "cultura burgesa» $\mathrm{i}$ "cultura proletària». ${ }^{26}$ La cultura té la seva pròpia autonomia i no es redueix a la seva simple instrumentalització per una o altra classe o grup en conflicte. En el seu dinamisme bistòric, la cultura duu sempre -com a creació del poble- un germen aclassista $i$ alliberador. Però aquesta vocació només es tealitza, segons P. Freire, quan un grup oprimit, en alliberar-se, no cau en nous esquemes d'opressió més o menys inspirats en el model de dominació anterior. ${ }^{n}$ L'oprimit, en alliberar-se, ha d'anar forjant el seu propi model d'allibera* ment $i$ aquest serà tant més progressista com més s'aptopi a la utopia

26. "El problema es mucbo más complejo», diuen A. C. Comín i J. García Nieto en referir-se a aquesta útima dicotomia (Juventud obrers y conciencia de clase, op. cit., p. 37).

27. Cal, això no obstant, tenir en compte que «el fenomen de la immigració al nostre país, immigració que s'estableix sobre una societat històticanent desenvolupada però políticament oprimida..., no s'adapta al model clàssic: país colonitzador o metròpoli-país colonitzat (país subdesenvolupat)», com diu un text collectiu a la revista Alliberament, agost de 1974, núm. 1, pp. 6.19, reproduint a Quaderns d'alliberament, op. cit., pp. 157-158. 
de l'alliberament universal i, per tant, aclassista. El resultat no setia la creació o reorganització d'una nova cultura, sinó el seu alliberament i universalització. Tots els homes - en altres paraules - podrien continuar mirant vers un passat com a seu $i$ veient la mateixa terra, encara que amb ulls nous.

\section{El nacionalisme romàntic i la utopia}

En aquest context, l'ambigüitat de l'expressió «nacionalisme romàntic» o «amor a la terra» reprèn tota la seva significació $i$ configuraria l'autonomia del fet cultural, allò que permet extreure del passat la utopia que ha d'informar tot projecte històric. Per això mateix nosaltres preferim parlar -en l'àmbit cultural- de cultura popular, cultura oprimida i alliberament caltural, més que de lluita de classes, terme més propi de l'àmbit polític. Es evident, això no obstant, que sense les degudes mediacions polítiques i econòmiques totes aquestes consideracions s'esfondren.

La cultura en si no és una ideologia, a pesar que, actualment, viu captiva d'ideologies de dominació. Amb la lluita política i la lluita ideològica la cultura es transforma i roman. La cultura està lligada al sorgiment i desenvolupament de la mateixa subjectivitat (mediatitzada per la personalitat, fet eminentment social). Nosaltres tomanem, igual que ella, al llatg de la històtia. Heus ací la importància $\mathrm{i}$ el realisme de la utopia per identificar-nos a través del temps, més enllà de tota ideologització de la cultura.

\section{Qui s'integra?}

La distinció que establim entre cultura $i$ aculturació respon al doble esquema estàticodinàmic les arrels del qual són la mateixa subjectivitat. El subjecte és alhora comunicació $\mathrm{i}$ identizat. No som per a nosaltres més que el que aconseguim comunicar i comunicar-nos mitjançant els altres. La cultura, com a llenguatge social de l'home amb els altres i amb ell mateix, no pot convertir-se en llenguatge intern si no es converteix en llenguatge per a algú: un grup, una comunitat. No pot integrar-nos a una acció històrica si no constitueix finalment, i respectant la seva pròpia dinàmica, el llenguatge de tota una societat. No és possible a la llarga la separació, l'oblit o la confrontació cultural en una mateixa societat sense que aquesta societat finalment s'enderroqui i es reintegri en una altra societat. El procés acabaria amb una pèrdua d'identitat per a tothom, no 
solament per als immigrats. La mera adaptació de la llengua com a mecanisme instrumental $i$ no com a mecanisme expressiu per part dels nonatius, constituiria un engany per als natius que la reclamen com a seva. No es pot ésser turista en la societat on un es troba inserit econòmicament i políticament. L'expressió "terra», "amor a la terra», deixarien de ser un projecte i perdrien el seu sentit real per a tothom, perquè un mateix espai geogràfic seria interpretat diversament $i$ en forma excloent per més d'una collectivitat. La paraula «història» o «passat» es convertiria en l'esdevenir impersonal d'un altre. El buidament de la pròpia cultura correria el risc de suplir-se aleshores amb un etnocentrisme irracional o un nacionalisme bellicista, base de nous racismes o colonialismes.

No és possible, per tant, la coexistència pacífica o pactada en aquest terreny, $i$ com que és impossible a la llarga una identitat cultural sana per part de dues o més cultures que comparteixin una mateixa terra, un mateix pa, una mateixa estructura de producció i de poder, per aixó es. tracta d'un gran desafiament $\mathrm{i}$ existeix el debat. L'única solució és caminar - sense dominis de cap mena $\mathrm{i}$ amb respecte vers tots els grups $i$ les seves expressions-- cap a un nou projecte cultural, i defunir quin seria el seu entroncament amb el passat (el seu principal nucli integrador), fent coincidir aquesta elecció amb l'alliberament de tothom.

\section{Conclusio}

Encara que la inspiració de la doble dinàmica d'integració (la de la cultura catalana al fet migratori i la de la immigració al fet català) ha estat fins ara d'origen català, l'haurien de definir en endavant els seus majors subjectes: les masses immigrades. Amb un desavantatge inicial po. derós: no van venir a aquest país per una inclinació natural, sinó econòmi* ca i laboral. L'altre desavantatge, això no obstant, és més greu: a pesar d'ésser també oprimida, la cultura catalana té un fort component de dominació, perquè no és solament la cultura dels «altres espanyols» discrimi* nats $\mathrm{i}$ allunyats dels centres de decisió política, sinó que no és encara la cultura majoritària dels «altres catalans».

\section{Pere Negre}

Departament de Sociologia

Universitat de Barcelona (Pedralbes)

Barcelona 